Original Article

\title{
INTRANASAL DELIVERY OF ARTEMETHER FOR THE TREATMENT OF CEREBRAL MALARIA
}

\author{
SUMAN RAMTEKE*, ROSHNI UBNARE, NAVENEET DUBEY, ANJITA SINGH
}

School of Pharmaceutical Sciences, Rajiv Gandhi Proudyogiki, Vishwavidyalaya, Bhopal. 462036, Madhya Pradesh

Email: sapna1731@rediffmail.com

Received: 21 Feb 2018 Revised and Accepted: 17 Jul 2018

\begin{abstract}
Objective: Nasal delivery provides a route of entry of drug to the brain that circumvents the obstacle for blood-brain barrier allowing direct drug delivery to the central nervous system via olfactory neurons. The objective of work was to prepare solid lipid nanoparticles of antimalarial drug artemether for brain delivery through olfactory delivery route for treatment of cerebral malaria.
\end{abstract}

Methods: Artemether containing solid lipid nanoparticles were prepared with soya lecithin and poloxamer 407 with a hot homogenization method followed by solvent injection technique. The prepared solid lipid nanoparticles were characterized by their shape, particle size, zeta potential, encapsulation efficiency total drug content and drug release study.

Results: These solid lipid nanoparticles were observed spherical in shape in scanning electron microscopy, the optimized size was found to be $211.6 \mathrm{~nm}$ (Polydispersity Index PI<0.415), with $-27 \mathrm{mV}$ zeta potential value. The maximum \% yield of the formulation was found to be found $49 \%$. The maximum entrapment efficiency was $82 \%(\mathrm{w} / \mathrm{w})$, and optimized formulation showed $98.07 \pm 1.521 \%$ drug release form formulation. In vivo studied were conducted on wistar rats after administration of artemether containing solid lipid nanoparticles intranasally and compared with plain artemether solution administered orally. The results of optimized formulation showed the value of biological half-life ( $\mathrm{T}_{1 / 2}$ ) was $4.95 \mathrm{~h}$, maximum serum concentration $\mathrm{C}_{\max }$ was $644.60 \mathrm{ng} / \mathrm{ml}$, time for drug to reach peak plasma concentration $\mathrm{T}_{\max }$ was $1 \mathrm{~h}$ volume of distribution (Vd) was $2.7 \mathrm{l} / \mathrm{kg}$, body clearance $(\mathrm{Cl})$ was $0.37 \mathrm{lh} / \mathrm{kg}$ and Area under curve $[\mathrm{AUC}]_{0^{\circ}}$ was $3970.5 \mathrm{nghr} / \mathrm{ml}$ for formulation.

Conclusion: The results revealed that the brain: plasma concentration ratio was higher after intranasal administration of solid lipid nanoparticles (SLNs) of artemether than the oral route. In conclusion, the intranasal administration of lipid nanoparticles of artemether could provide complete protection against cerebral malaria.

Keywords: Solid lipid nanoparticles, Cerebral malaria, Intranasal administration, Artemether, Glyecerylmonosterate, Lecithin

(C) 2018 The Authors. Published by Innovare Academic Sciences Pvt Ltd. This is an open access article under the CC BY license (http://creativecommons.org/licenses/by/4.0/] DOI: http://dx.doi.org/10.22159/ijpps.2018v10i9.25408

\section{INTRODUCTION}

Malaria is an infectious disease caused by the Plasmodium genus of a protozoan parasite. During the course of the disease, an initial asymptomatic infection of the liver is followed by parasites invasion into red blood cells, causing clinical symptoms of malaria. The most severe complication of Plasmodium falciparum infection is cerebral malaria, which implies the presence of neurological features, especially impaired consciousness. In cerebral malaria, sequestration of the parasitized erythrocytes in the brain microvasculature reduces the blood flow and triggers a severe immune pathological response [1, 2]. Existing treatments for malaria include a limited number of clinically effective antimalarial agents. The artemether is a potent and rapidly acting antimalarial agent which is enlisted in WHO List of Essential Medicines [3] for the treatment of severe multiresistant malaria. It is active against $P$. vivaxas well as chloroquine-sensitive and chloroquine-resistant strains of $P$. falciparum. It is also indicated in the treatment of cerebral malaria. Currently, artemether is available as tablets for oral therapy and as an intramuscular oily injection for the treatment of severe malarial infections. The oral bioavailability of artemether is low $(\sim 40 \%)$ due to its poor aqueous solubility and degradation in stomach acids [4] whereas intramuscular injection suffers from disadvantages such as pain on injection and; slow and erratic absorption on intramuscular administration [5]. These shortcomings of therapy could be overcome by the development of navel carriers or by administration of a drug through alternative route like rectal or transdermal administration of antimalarials have been investigated $[6,7]$. On the other side drug delivery to the brain is made difficult due to the presence of blood-brain barrier (BBB), which is formed by tight junctions within the capillary endothelium of the vertebrate brain. Since cerebral malaria gets fetal within a few days of infection hence immediate treatment is necessary. Intranasal administration would offer a noninvasive alternative to traditional invasive intracerebro- ventricular injection as a direct delivery of therapeutics to the central nervous system, effectively bypassing the blood-brain barrier (BBB). Recently intranasal drug delivery is recognized to be a useful and reliable alternative to oral and parenteral routes. The drug delivery into central nervous system through intranasal route has been reported [8-11] either in humans or animal models of Alzheimer's disease [12,13], brain tumours [14, 15], epilepsy [16], pain [17] and sleep disorders [18], in proposed work first time we tried to deliver drug to Central nerves system (CNS) in the treatment of cerebral malaria. The nanoparticulate system widely investigated because of many advantages such as controlled drug release pattern, drug targeting ability, and smaller size, improvement of therapeutic efficacy and reduction of toxicity. Recently the Jain el al.[2014] reported the optimization of the artemether loaded nanostructure lipid carriers for intranasal delivery [19]. In present work we tried to prepare solid lipid nanoparticles for intranasal delivery of the drug. These solid lipid nanoparticles would have great potential to deliver the drug to CNS and could show controlled drug release and site-specific drug targeting. These new delivery strategies could increase the uptake of artemether in the infected brain and could improve the patient compliance and therapeutic index of treatment therapy.

\section{MATERIALS AND METHODS}

\section{Materials}

Artemether was procured as a gift sample from IPCA laboratory (India), Glyecerylmonosterate (GMS) was purchased from $\mathrm{CDH}$ (India). Lecithin was purchased from Across chemicals (India). Pluronic F127 was purchased from Himedia (India). All other reagents used in this study were of analytical grade.

Preparation of solid lipid nanoparticles [20]

Solid lipid nanoparticles containing artemether were prepared using the hot homogenization method. The aqueous phase was prepared by 
dissolving the surfactant (lecithin) and co-surfactant (poloxamer 407) in $50 \mathrm{ml}$ of double distilled water. The organic solution was prepared by completely dissolving the artemether and lipid glyecerylmonosterate in $5 \mathrm{ml}$ of water-miscible solvent (methanol) in a water bath at $70^{\circ} \mathrm{C}$, which is above the melting point of the glyecerylmonosterate (GMS). The resultant organic solution was injected into $50 \mathrm{ml}$ of an aqueous phase containing the surfactant, with mechanical stirring (Remi Instruments Ltd, India) at $1,000 \mathrm{rpm}$ at $61{ }^{\circ} \mathrm{C}$ for $1 \mathrm{~h}$. The nanosuspension formed was allowed to cool at room temperature. As the temperature drops under such conditions, the lipid droplets solidify producing small lipid nanoparticles. The prepared nanoparticles were purified by centrifugation at $15000 \mathrm{rpm}$ for $10 \mathrm{~min}$ using ultracentrifuge (Optimamax-XP, Backman coulter (USA) freeze-dried (Wizard 2 Advantage plus, VerTis USA) and stored in the refrigerator for further use. Various variables such as the lipid, surfactant and co-surfactant concentrations were considered during the optimization of the formulation (table 1).

\section{Characterization of solid lipid nanoparticles}

\section{Surface morphology}

Surface morphology of solid lipid nanoparticles was confirmed by Scanning electron microscopy (JEOL JSM6390 A) with auto fine coater (JEOL1600). The sample was scanned at 5-15 Kv electron beam. SEM photograph of solid lipid nanoparticles is given in fig. 1 .

\section{Size and size distribution}

The average particle sizes of the solid lipid nanoparticles dispersion were determined using particle size analyzer Zetasizer (Malvern Instruments, UK). The sample of dispersion was diluted to $1: 9 \mathrm{v} / \mathrm{v}$ with double distilled water to ensure that the light scattering intensity was within the instrument's sensitivity range (table 1). Polydispersity index which is a range of measurement of particle sizes within the measured sample was calculated as the weight average molecular weight divided by the number average molecular weight and given in table 1.

\section{Zeta potential}

Zeta potential value shows the electrokinetic potential of colloidal systems. The significance of zeta potential is that its value can be related to the stability of colloidal nanoparticles. The zetapotential values of formulations are given in table 1 .

\section{Yield of lipid nanoparticles}

The total amount of nanoparticles obtained were weighed individually for each batch and percentage yield was calculated taking into consideration the weight of drug and polymer by using the following formula and observations are shown in table 1.

$$
\% \text { Yeild }=\frac{\text { Amount of dried solid lipid nanoparticles }}{\text { Amount o polymer }+ \text { surfactant }+ \text { drug }} \times 100
$$

\section{Percent drug entrapment efficiency}

The entrapment efficiency was determined by analyzing the free drug content in the supernatant obtained after centrifuging the lipid nanoparticulate suspension in a high-speed cooling centrifuge (Remi instruments Ltd, India) at $1,7000 \mathrm{rpm}$ for $1 \mathrm{~h}$ at $0^{\circ} \mathrm{C}$. The entrapment efficiency was calculated as follows and shown in table 1.

$$
\% \text { Entrapment efficiency }=\frac{\text { Amount of drug in solid lipid nanoparticles }}{\text { Amount of initial drug added }} \times 100
$$

\section{Total drug content}

The total amount of drug in the formulation was determined by dissolving $1 \mathrm{ml}$ of the formulation in $10 \mathrm{ml}$ of methanol. The amount of artemether in each sample was determined using a UV spectrophotometer (1700, Shimadzu, Japan) by measuring the absorbance at $240 \mathrm{~nm} \lambda \max$. The total drug content was calculated using the following equation and given in table 1.

Total drug content $=$ Concentration $\mathrm{X}$ Dilution Factor X Volume of Formulation ---Eq 3

\section{In vitro drug released study}

In vitro release studies were performed using modified Franz diffusion cell. Dialysis membrane of $2.4 \mathrm{~nm}$ pore size, molecular weight cutoff between 12,000-14,000 was used for the study. Nanoparticulate formulation $(10 \mathrm{mg}$ ) was dispersed in $1 \mathrm{ml}$ of dissolution medium and placed in the donor compartment and the receptor compartment was filled with dialysis medium $(25 \mathrm{ml}$ phosphate buffer, $\mathrm{pH}$ 6.4). At fixed time intervals, $2 \mathrm{ml}$ of the sample was withdrawn at different time intervals for $6 \mathrm{~h}$ through side tube from receiver compartment. Fresh medium was added to maintain a constant volume. The artemether content was estimated using Shimadzu UV/visible spectrophotometer at wavelength $254 \mathrm{~nm}$ and the percent drug release at the particular interval was calculated. The release study was also carried out for a pure drug for comparison with artemether formulation. The percent cumulative drug release of optimized solid lipid nanoparticles and pure drug are shown in fig. 2.

\section{In vivo studies}

The in vivo intranasal delivery of optimized formulation was assessed on wistar rats (aged 4-5 mo) of either sex weighing 200$250 \mathrm{~g}$. Animals were procured from the animal house and had free access to food and water throughout the duration of the study. The study was carried out under the guidelines complied by CPCSEA (committee for the purpose of control and supervision of experiments on animals), Ministry of Social Justice And Empowerment, Government of India, and all the study protocols were approved by Institutional Animal Ethical Committee (PH/IAEC/VNS/2K12/30 of VNS) of VNS Institute of Pharmacy, Bhopal, India.

The rats were divided into four groups and four rats were selected for each group in such a way that same rat can be used for analyzing the concentration of artemether in plasma and in cerebrospinal fluid on each time interval. While administering the formulation and drug suspension; the rats were anaesthetized prior by inhalation of diethyl ether. The rats were administered lipid nanoparticles intranasally and suspension of artemether orally. The $0.2 \mathrm{ml}$ of distilled water dispersed with a weighed quantity of formulations (containing an equivalent quantity of dose 1 and dose 2) and pure drug (dose 1) was selected for both nasal as well as oral delivery. The animal dose of the drug was calculated based on body surface area [21]. As the small nano size intranasal formulation was selected for to provide fast effect at a low dose, therefore, half and $1 / 4$ concentration of marketed dose were tried on mice. The first group was treated as control and administered with placebo formulation intranasally, the second groups was administered intranasally with formulation containing dose equivalent to $0.154 \mathrm{mg} / \mathrm{kg}$ (Dose 1which is $1 / 2$ of marketed dose) of artemether, third group was also intranasally administered with formulation containing $0.077 \mathrm{mg} / \mathrm{kg}$ (Dose 2-which is $1 / 4$ of marketed dose) of artemether which is half concentration of the first dose, fourth group was orally administered pure drug solution of dose $1(0.154 \mathrm{mg} / \mathrm{kg})$ of artemether. After administration through intranasal and oral route, the artemether concentration was analyzed separatelyin the brain and in plasma.

At different time intervals like $0.25,0.5,1,2,4,6,8 \mathrm{~h}$, the CSF was withdrawn from all animals in different group, prior to CSF collection, the fur on the neck region of the rat was removed using oster clipper and animal was placed in an induction chamber and anaesthetized with diethyl ether sprayed on cotton bed placed in induction chamber. The position of the animal's head was maintained downward at approximately $45^{\circ}$. A depressible surface with the appearance of a rhomb between the occipital protuberance and the spine of atlas becomes visible when cotton embedded in ethanol $(70 \%)$ is rubbed over the surface. A needle connected to draw syringe was inserted horizontally and centrally into the cisterna magna for the cerebrospinal fluid (CSF) collection without making any incision in this region. A change in the resistance along this way can be easily felt. A gentle aspiration will make the CSF flow through the needle. The colorless CSF sample is slowly drawn into the syringe and color of the CSF was closely observed to avoid any possible blood contamination.

After CSF sampling, same animals were used to collect plasma samples at different time intervals of $0.25,0.5,1,2,4,6,8 \mathrm{~h}$ (fig. 4), for the collection of plasma, the anesthetized rat was held in hand with its head pointing down. Skin from the eyeball was pulled away so that the 
eyeball is protruding out of the socket as much as possible. Tip of the fine capillary was inserted into the corner of the eye socket underneath the eyeball; directing the tip at a 45-degree angle towards the middle of the eye socket. The capillary was rotated between fingers, the gentle downward pressure was also applied and then released until the vein was broken and blood was visualized entering the capillary. Blood was collected in a centrifuge tube having $20 \mu \mathrm{l}$ of heparin as an anticoagulant. Plasma was then separated from blood by centrifuging in cooling centrifuge at 5700 RPM for $15 \mathrm{~min}$.

For extraction of artemether from blood, the blood samples were mixed with heparin (anticoagulant) in centrifuge tubes and then centrifuged at $5700 \mathrm{rpm}$ for $15 \mathrm{~min}$. The plasma samples obtained were then mixed with methanol and further centrifuged for $15 \mathrm{~min}$ the extracted aliquots were then filtered and derivatized for HPLC analysis. The same procedure was repeated for CSF samples for estimation of the concentration of artemether in cerebrospinal fluid by HPLC method [22]. The mobile phase selected for analysis was acetonitrile: water (45:55), the flow rate was $0.5 \mathrm{ml} / \mathrm{min}$ and the detection wavelength was selected at $254 \mathrm{~nm}$.

\section{RESULTS AND DISCUSSION}

Cerebral malaria comprises the clinical reflections of plasmodium falciparum malaria which causes mutations in mental status and sometimes, coma. It is an intense disease of the brain, causing ring-like lesions in the brain, accompanied by fever. Artemether is a frontline drug used in the treatment of malaria. The oral bioavailability of artemether is low due to its poor aqueous solubility and degradation in acidic $\mathrm{pH}$ of the stomach. In present work, we tried to prepare solid lipid nanoparticles for intranasal delivery of artemether to provide effective treatment in case of cerebral malaria.

Solid lipid nanoparticles containing artemether were prepared using the hot homogenization method. The organic phase with drug and lipid was injected into an aqueous phase containing contacting surfactant and co-surfactant. The nanosuspension formed was allowed to cool at room temperature centrifuged and freeze-dried for further use. The prepared nanoparticles were characterized for particle size, polydispersity index (PDI), zeta potential, entrapment efficiency, total dug content, percent yield and in vitro drug release study.

Surface morphology of formulation was determined with scanning electron microscopy and the photograph is shown in fig. 1 . The scanning electron microscopy of formulations showed spherical and smooth surface of particles.

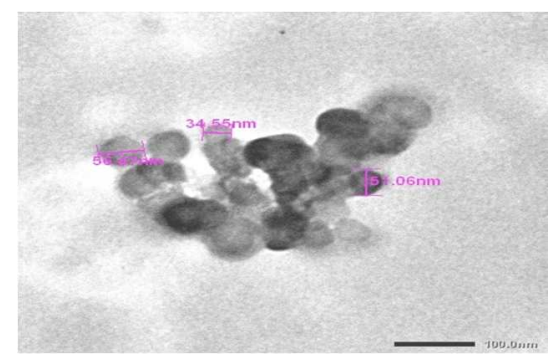

Fig. 1: Scanning electron microscopy of solid lipd nanoparticles

Table 1: Characterization and optimization of solid lipid nanoparticles

\begin{tabular}{|c|c|c|c|c|c|c|c|c|c|c|}
\hline $\begin{array}{l}\text { Formulat } \\
\text { ion code }\end{array}$ & $\begin{array}{l}\text { Lipid } \\
\text { concentration } \\
\left(\mathrm{GMS}^{*} \mathbf{m g}\right)\end{array}$ & $\begin{array}{l}\text { Co-surfactant } \\
\text { concentration } \\
\text { (poloxamer } \\
\% \text { ) } \\
\end{array}$ & $\begin{array}{l}\text { Surfactant } \\
\text { concentration } \\
\text { (Soya lecithin } \\
\% \text { ) } \\
\end{array}$ & $\begin{array}{l}\text { Stirring } \\
\text { speed } \\
\text { (RPM) }\end{array}$ & $\begin{array}{l}\text { Size } \\
(\mathrm{nm})\end{array}$ & $\begin{array}{l}\text { PDI* } \\
*\end{array}$ & $\begin{array}{l}\text { Zeta } \\
\text { potentia } \\
\text { l }\end{array}$ & $\begin{array}{l}\% \text { total } \\
\text { drug } \\
\text { content }\end{array}$ & $\begin{array}{l}\text { \%entrapmen } \\
\text { t efficiency }\end{array}$ & $\begin{array}{l}\text { \%Yiel } \\
\text { d }\end{array}$ \\
\hline F-1 & 10 & 0.5 & 0.5 & & 342.2 & 0.313 & -25.7 & 54.21 & 72.10 & 35.12 \\
\hline F-2 & 20 & 0.5 & 0.5 & & 358.7 & 0.489 & -18.1 & 53.29 & 71.04 & 42.23 \\
\hline$F-3$ & 30 & 0.5 & 0.5 & & 361.8 & 0.297 & -24.6 & 47.37 & 78.89 & 44.21 \\
\hline F-4 & 40 & 0.5 & 0.5 & & 307.8 & 0.308 & -23.3 & 59.24 & 79.23 & 41.04 \\
\hline F-5 & 50 & 0.5 & 0.5 & & 259.9 & 0.448 & -17.8 & 60.10 & 80.04 & 39.19 \\
\hline F-6 & 60 & 0.5 & 0.5 & & 211.6 & 0.415 & -27.2 & 60.98 & 80.43 & 43.21 \\
\hline F-7 & 70 & 0.5 & 0.5 & & 261.1 & 0.304 & -28.2 & 54.23 & 76.35 & 45.45 \\
\hline F-8 & 80 & 0.5 & 0.5 & & 245.1 & 0.316 & -20.1 & 61.09 & 66.16 & 39.11 \\
\hline F-9 & 90 & 0.5 & 0.5 & & 226.3 & 0.312 & -19.0 & 62.11 & 79.99 & 37.96 \\
\hline F-10 & 100 & 0.5 & 0.5 & & 284.0 & 0.585 & -22.9 & 59.25 & 78.10 & 48.82 \\
\hline F-11 & & 0.75 & 0.5 & & 250.0 & 0.479 & -21.3 & 57.10 & 70.31 & 40.80 \\
\hline F-12 & & 1.0 & 0.5 & & 219.8 & 0.723 & -27.8 & 59.99 & 66.16 & 32.16 \\
\hline F-13 & & 0.5 & 0.5 & & 273.3 & 0.623 & -20.0 & 60.91 & 59.70 & 36.11 \\
\hline F-14 & & 0.5 & 0.75 & & 263.7 & 0.321 & -22.3 & 62.11 & 69.80 & 37.16 \\
\hline F-15 & & 0.5 & 1.0 & & 258.2 & 0.432 & -23.8 & 57.10 & 75.02 & 41.00 \\
\hline F-16 & & 0.5 & 1.0 & 700 & 389.9 & 0.277 & -21.0 & 49.91 & 78.19 & 39.99 \\
\hline F-17 & & 0.5 & 1.0 & 800 & 303.7 & 0.321 & -23.1 & 46.16 & 73.46 & 36.00 \\
\hline F-18 & & 0.5 & 1.0 & 900 & 289.2 & 0.551 & -24.3 & 58.19 & 76.1 & 42.98 \\
\hline F-19 & & 0.5 & 1.0 & 1000 & 215.6 & 0.492 & -25.2 & 59.98 & 82.64 & 36.29 \\
\hline F-20 & & 0.5 & 1.0 & 1100 & 250.4 & 0.472 & -22.0 & 52.10 & 69.85 & 42.45 \\
\hline $\mathrm{F}-21$ & & 0.5 & 1.0 & 1200 & 282.5 & 0.522 & -24.0 & 56.29 & 73.68 & 49.68 \\
\hline
\end{tabular}

GMS* $=$ Glyecerylmonosterate **PDI-Polydispersity index

The particle size and polydispersity index were found to be $211.6 \mathrm{~nm}$ and 0.415 for optimized formulation. The particle size was observed in the nano range and found to be significantly affected by an increase in the amount of lipid, this may be attributed to the inability of the surfactant and co sufcatant solution to stabilize the emulsion at a very low concentration $(0.5 \%)$, however higher $(0.7-1 \%)$ concentration of poloxamer and lecithin was sufficient to stabilize the emulsion even with a high lipid load of $80 \mathrm{mg}$, with a consistent particle size. The zeta potential value of optimized formulation was- $27 \mathrm{mV}$ (table 1) which is attributed to the negative charge of lipid nanoparticles [23]. The maximum $\%$ yield of the formulation was found to be $49 \%$.

The maximum entrapment efficiency was $82 \%$ (w/w)(table 1). Entrapment efficiency was found to be increased with increase in the amount of lipid (table 1), which may be due to a greater availability of lipid to encapsulate the drug. The increase in surfactant and co-surfactant concentration reduces the interfacial tension between the lipid and aqueous phase causes the formation of a large number of small particles with the large surface area which increases the entrapment efficiency of formulations.

In vitro release studies of artemether contacting solid lipid nanoparticles were carried out at $37 \pm 1{ }^{\circ} \mathrm{C}$ for optimized formulation using a phosphate buffer of $\mathrm{pH} 6.4$ as dissolution medium. The cumulative percent release profile of artemether is given in fig. 2 . The optimized formulation showed $98.07 \pm 1.521 \%$ drug release form nanoformulation. The release of of artemether was much higher than a pure drug, which could be due to smaller particle size and sustain release properties of solid lipid nanoparticles. The result showed that the optimized formulation gives the most consistent drug release pattern, which showed that formulation is able to release artemether for long period of time which would be helpful for the eradication of all 


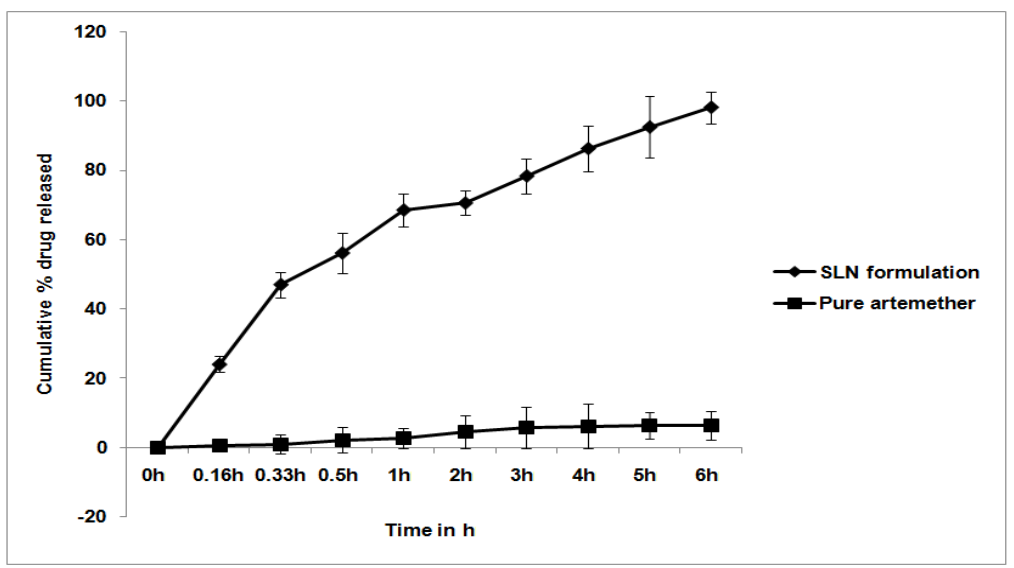

Fig. 2: Release profile of pure artemether and artemether from solid lipid nanoparticles $n=3 \pm S D, S D=$ standard deviation

The prepared nanoparticulate formulation was finally assessed for in vivo performance on wistar rats. The objective of in vivo study was to evaluate different pharmacokinetic parameters of intranasal nanoformulations and compare the efficacy with an oral solution of artemether. The drug-containing formulations were administered intranasally and the same dose of the pure drug was given by oral route to observe the concentration difference in the brain after administration of the same dose through a different route. The formulation containing half concentration of dose was also evaluated for efficacy along with optimized formulation.

In vivo study were conducted on wistar rats after administration of artemether containing solid lipid nanoparticles intranasally and compared with plain artemether suspension administered orally. After administration of formulation through both intranasal as well oral routes, the concentration of artemether was analyzed in cerebrospinal fluid and in plasma. After collection of plasma and cerebrospinal fluid (CSF) samples at different time intervals, the samples were derivatized for HPLC analysis. Derivatization involved an acid decomposition with hydrochloric acid to produce a UVabsorbing product, and $\alpha, \beta$-unsaturated decalone [8-methyl-5-(2propanalyl) decalin-4ene-3one], which gave absorbance at wavelength $254 \mathrm{~nm}$.

The results showed that plasma $\mathrm{T}_{1 / 2}$ was found to be $4.95 \mathrm{~h}$ when nanoparticles administered intranasally, while it was found to be 2.4 $\mathrm{h}$ when artemether suspension administered orally which is attributed to the capability of the intranasal formulation to sustain the release and maintain the effective concentration of artemether in cerebrospinal fluid. The higher concentration $(644.6 \mathrm{ng} / \mathrm{ml})$ was achieved in brain after intranasal administration of artemether containing formulation in $1 \mathrm{~h}$ than that achieved $(69.20 \mathrm{ng} / \mathrm{ml})$ in 4 $\mathrm{h}$ after same dose of oral administration of artemether suspension which is attributed to nanosize of formulation that may enter the brain directly when administered through intranasal route which will not only provide fast effective action, it would also release the drug in brain in a sustained manner and would be able to remove malaria parasite from brain.

Table 2: Details of formulations administered through a different route and analysis of drug in the brain (cerebrospinal fluid) and plasma

\begin{tabular}{llll}
\hline Group(s) & Group & Route & Concentration analysised in \\
\hline Group-I & Placebo SLN formulation & IN & Brain \\
(Control) & Placebo SLN formulation & IN & Blood \\
Group-II & SLN formulation (dose $0.154 \mathrm{mg} / \mathrm{kg}$ ) & IN & Brain \\
& SLN formulation (dose $0.154 \mathrm{mg} / \mathrm{kg}$ ) & IN & Blood \\
Group-III & SLN formulation(dose $0.077 \mathrm{mg} / \mathrm{kg})$ & IN & Brain \\
& SLN formulation (dose $0.077 \mathrm{mg} / \mathrm{kg})$ & IN & Blood \\
Group-IV & Artemether drug solution(dose $0.154 \mathrm{mg} / \mathrm{kg})$ & Oral & Brain \\
& Artemether drugSolution(dose $0.154 \mathrm{mg} / \mathrm{kg})$ & Oral & Blood \\
\hline
\end{tabular}

SLN= solid lipid nanoparticles, IN = intranasal

Table 3: Pharmacokinetic parameters of artemether containing solid lipid nanoparticles and pure drug solution after intranasal and oral administration ( $\mathrm{n}=4 \pm \mathrm{SD}, \mathrm{SD}=$ standard deviation)

\begin{tabular}{|c|c|c|c|c|c|c|}
\hline \multirow[t]{4}{*}{ Pharmacokinetic parameters } & \multicolumn{6}{|c|}{ Calculated values for blood and CSF samples } \\
\hline & \multicolumn{3}{|c|}{ CSF } & \multicolumn{3}{|l|}{ Plasma } \\
\hline & \multirow[t]{2}{*}{ Oral } & \multicolumn{2}{|l|}{ IN } & \multirow[t]{2}{*}{ Oral } & \multicolumn{2}{|l|}{ IN } \\
\hline & & Dose 1 & Dose 2 & & Dose 1 & Dose 2 \\
\hline $\mathrm{K}$ (ng/hr) & 0.287 & 0.14 & 0.19 & 0.46 & 0.16 & 0.24 \\
\hline$t_{1 / 2}(h)$ & 2.4 & 4.95 & 3.6 & 1.5 & 4.3 & 3.01 \\
\hline $\mathrm{Cmax}(\mathrm{ng} / \mathrm{ml})$ & 69.20 & $644.60^{* * *}$ & 247.04 & 124.05 & 271.75 & 104.85 \\
\hline $\operatorname{Tmax}(\mathrm{h})$ & 4 & 1 & 1 & 1 & 2 & 2 \\
\hline $\mathrm{Vd}(\mathrm{l} / \mathrm{kg})$ & 10.70 & 2.7 & 5.2 & 4.7 & 5.39 & 8.3 \\
\hline $\mathrm{Cl}(\mathrm{l} . \mathrm{hr} / \mathrm{kg})$ & 2.1 & 0.37 & 0.98 & 3.07 & 0.86 & 1.9 \\
\hline$[\mathrm{AUC}]_{0}{ }^{\infty}(\mathrm{nghr} / \mathrm{ml})$ & 700.7 & 3970.54 & 1540.43 & 500.9 & 1783.0 & 770.6 \\
\hline Dose $(\mathrm{mg} / \mathrm{kg})$ & 0.154 & 0.154 & 0.077 & 0.154 & 0.154 & 0.077 \\
\hline
\end{tabular}

$\mathrm{IN}=$ intra nasal, $\mathrm{CSF}=$ cerebrospinal fluid, $\mathrm{C}_{\max }=$ maximum serum concentration, $\mathrm{t}_{1 / 2}=$ biological half-life, $\mathrm{T}_{\max }=$ time for peak plasma concentration, $\mathrm{Vd}=$ Volume of distribution, $\mathrm{AUC}=$ area under the curve, $\mathrm{Cl}=$ body clearance, $\mathrm{K}=$ elimination rate constant, $* * *=\mathrm{P}<0.001$ 
The pharmacokinetic parameters like maximum serum concentration $\left(\mathrm{C}_{\max }\right)$, time for peak plasma concentration $\left(\mathrm{T}_{\max }\right)$, biological half-life $\left(\mathrm{T}_{1 / 2}\right)$, area under curve (AUC), body clearance $\left(\mathrm{C}_{\mathrm{L}}\right)$ and Volume of distribution $\left(\mathrm{V}_{\mathrm{d}}\right)$ were calculated from the individual cerebroipinal fluid (CSF) and plasma concentration-time profile experiments after intranasal and oral administration of formulations as shown in table 3 . The results of optimized formulation showed the value of half-life $\left(\mathrm{T}_{1 / 2)}-4.95 \mathrm{~h}\right.$, maximum serum concentration $\left(\mathrm{C}_{\max }\right)$ was $644.60 \mathrm{ng} / \mathrm{ml}$, time for peak plasma concentration ( $\mathrm{T}_{\max }$ ) was $1 \mathrm{~h}$, Volume of distribution $\mathrm{Vd}$ was $2.7 \mathrm{l} / \mathrm{kg}, \mathrm{Cl}-0.37 \mathrm{lhr} / \mathrm{kg}$ and area under curve [AUC] $0^{\infty}$ was $3970.5 \mathrm{nghr} / \mathrm{ml}$ for formulation.
When the pharmacokinetic parameters for the formulations of the same dose were compared the lower $\mathrm{T}_{\max }$ value for the brain $(1 \mathrm{hr})$ was observed as compared to blood ( $2 \mathrm{~h}$ ) which is attributed to the preferential nose to brain transport following intranasal administration. When the peak plasma concentration $\left(\mathrm{C}_{\max }\right)$ and area under curve (AUC) of brain concentrations of artemther solid lipid nanoparticles (SLN) formulation (intranasal) and artemether suspension (oral) were compared, the peak plasma concentration $\left(C_{\max }\right) 644.60 \mathrm{ng} / \mathrm{ml}$ and area under curve (AUC) $3970.5 \mathrm{nghr} / \mathrm{ml}$ of artemether SLN formulation were found to be significantly higher; this could be because of the direct transport of drug through olfactory route by bypassing BBB.

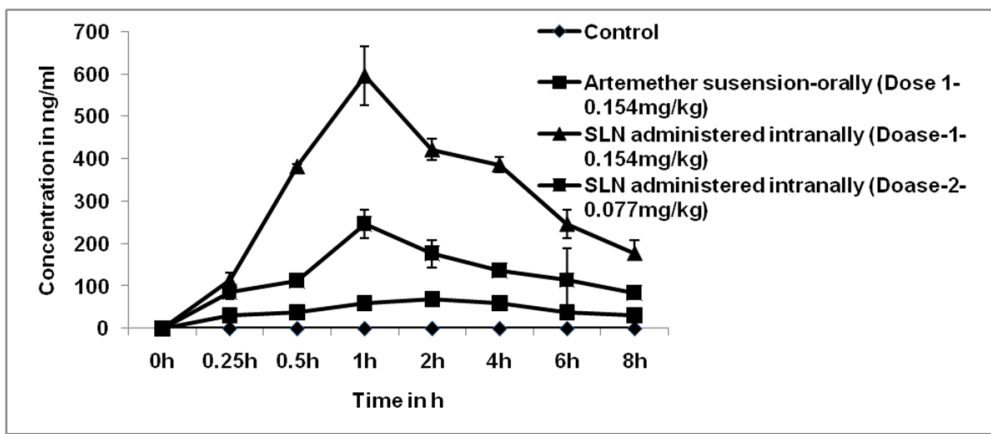

Fig. 3: Concentration of the drug in cerebrospinal fluid after intranasal and oral administration of formulations with different dose. $\mathrm{n}=4 \pm \mathrm{SD}, \mathrm{SD}=$ standard deviation, $\mathrm{SNL}=$ solid lipid nanoparticles)

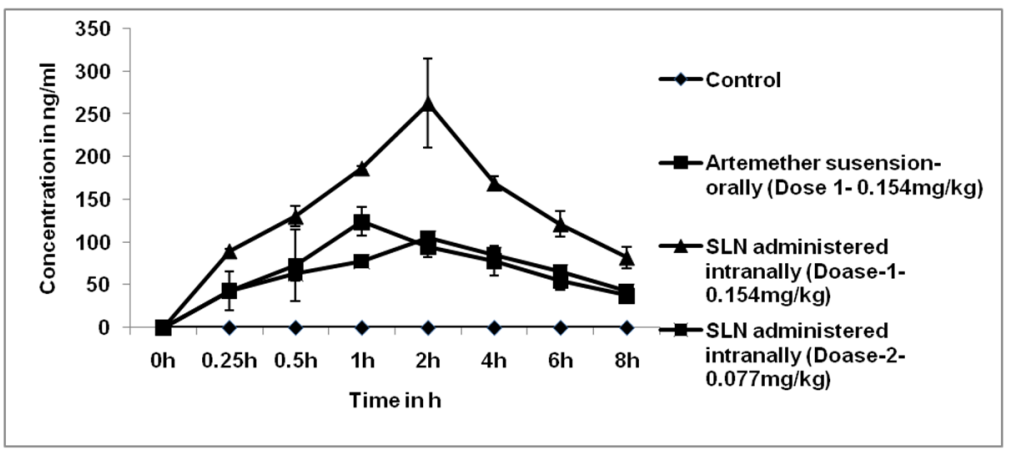

Fig. 4: Concentration of drug in plasma after intranasal and oral administration of formulations with different dose. $n=4 \pm S D, S D=$ standard deviation, $\mathrm{SNL}=$ Solid lipid nanoparticles)

The results also revealed that when solid lipid nanoparticles (SLN) formulation of artemether containing $0.077 \mathrm{mg}$ dose of drug was given through intranasal route showed higher concentration in CSF than artemether suspension $(0.154 \mathrm{mg}$ of dose) given orally, which again confirmed that through intranasal route artemther may directly reach the brain which reveals that formulations are effective at low dose and may be more effective than available marketed formulation. Data from in vivo experiments were analyzed statistically by one-way analysis of variance (ANOVA) with TukeyKramer multiple comparison post-test methods. The software used was GraphPad InStat. The statistically difference between groups was defined as $p<0.001$. The overall $p$-value was extremely significant $(p<0.0001)$.

\section{CONCLUSION}

The result of the study indicates that solid lipid nanoparticles could be a potential carrier for artemether delivery to the brain in the treatment of cerebral malaria. In vivo study proves that bioavailability of artemether from solid lipid nanoparticles formulation was far better than oral suspension of artemether. The study concluded that formulation with a half dose of intranasal preparation exhibit more concentration in brain than that of concentration achieved by the oral route. The results of the present study indicated that delivering artemether intranasally for targeting the CNS would be a promising approach for the treatment of cerebral malaria.

\section{ACKNOWLEDGEMENT}

Authors would like acknowledge the School of Pharmaceutical Sciences for providing the necessary facilities to carry out research work and University Grant Commission for providing a fund for research work. Authors are thankful to IPCA laboratory Mumbai, India for providing drug as a gift sample and VNS Institute of Pharmacy, Bhopal for proving experimental facilities for in vivo animal studies.

\section{AUTHORS CONTRIBUTIONS}

All authors had equally contributed the research work

\section{CONFLICTS OF INTERESTS}

\section{Declare none}

\section{REFERENCES}

1. Petersen E. Malaria chemoprophylaxis: when should we use it and what are the options? Expert Rev Anti-Infect Ther 2004;2:119-32.

2. Medana IM, Turner GDH. Human cerebral malaria and the blood-brain barrier. Int J Parasitol 2006;36:555-68. 
3. WHO. Available from: http://whqlibdoc.who.int/hq/2005/ a87017eng.pdf [Last accessed on 17 Jul 2007]

4. Karbwang J, Na-Bangchang $K$, Congpuong $K$, Molunto $P$, Thanavibul A. Pharmacokinetics and bioavailability of oral and intramuscular artemether. Eur J Clin Pharmacol 1997;52:307-10.

5. Hien TT, Davis TM, Chuong LV, Ilett KF, Sinh DX, Phu NH, et al. Comparative pharmacokinetics of intramuscular artesunate and artemether in patients with severe falciparum malaria. Antimicrob Agents Chemother 2004;48:4234-9.

6. Lin AJ, Ager JRAL, Klayman DL. Antimalarial activity of dihydroartemisinin derivatives by transdermal application. Am J Trop Med Hyg 1994;50:777-83.

7. Karunajeewa HA, Kemiki A, Alpers MP, Lorry K, Batty KT, Ilett $\mathrm{KF}$, et al. Safety and therapeutic efficacy of artesunate suppositories for treatment of malaria in children in Papua new guinea. Pediatr Infect Dis J 2003;22:251-6.

8. Chow H, Anavy N, Villalobos A. Direct nose-brain transport of benzoylecgonine following intranasal administration in rats. J Pharm Sci 2001;90:1729-35.

9. Dufes C, Olivier JC, Gaillard F, Gaillard A, Couet W, Muller JM. Brain delivery of vasoactive intestinal peptide (vip) following nasal administration to rats. Int J Pharm 2003;255:87-97.

10. Pires PC, Santos AO. Nanosystems in nose-tobrain drug delivery: A review of non-clinical brain targeting studies. J Controlled Release 2018;270:89-100.

11. Lakshmi PK, Prasanthi D, Veeresh B. Non-invasive delivery of protein and peptide drugs: a review. Asian J Pharm Clin Res 2017;109:25-33.

12. Jogani VV, Shah PJ, Mishra P, Mishra AK, Misra AR. The intranasal mucoadhesive microemulsion of tacrine to improve brain targeting. Alzheimer Dis Assoc Disord 2008;22:116-24.
13. Mantry S, Balaji. Formulation design and characterization of ropinirole hydrochloride microsphere for intranasal delivery. Asian J Pharm Clin Res 2017;10:195-203.

14. Hashizume R, Ozawa T, Gryaznov SM, Bollen AW, Lamborn KR, Frey 2nd WH, et al. New therapeutic approach for brain tumors: intranasal delivery of telomerase inhibitor GRN163. Neurol Oncol 2008;10:112-20.

15. Sakane T, Yamashita S, Yata N, Sezaki H. Transnasal delivery of 5fluorouracil to the brain in the rat. J Drug Target 1999;7:233-40.

16. Barakat NS, Omar SA, Ahmed AA. Carbamazepine uptake into rat brain following intra-olfactory transport. J Pharm Pharmacol 2006;58:63-72.

17. Westin U, Piras E, Jansson B, Bergström U, Dahlin M, Brittebo E, et al. Transfer of morphine along the olfactory pathway to the central nervous system after nasal administration to rodents. Eur J Pharm Sci 2005;24:565-73.

18. Yamada K, Hasegawa M, Kametani S, Ito S. Nose-to-brain delivery of ts-002, prostaglandin $\mathrm{d} 2$ analogue. J Drug Target 2007;15:59-66.

19. Jain K, Sood S, Gowthamarajan K. Optimization of artemetherloaded NCL for intranasal delivery using composit design. Drug Delivery 2014;22:1-15.

20. Ekambaram P, Sathali AA. Formulation and evaluation of solid lipid nanoparticles of ramipril. J Young Pharm 2011;3:216-20.

21. Shaw RS, Nihal M, Ahmad N. Dose translation from animal to human studies revisited. FASEB J 2007;22:659-66.

22. Muhia DK, Mberu EK, Watkins WM. Differential extraction of artemether and its metabolite dihydroartemisinin from plasma and determination by high-performance liquid chromatography. J Chromatography 1994;660:196-9.

23. Schwarz C. Solid lipid nanoparticles for controlled drug delivery II. Drug incorporation and physicochemical characterization. J Microencapsul 1999;16:205-13. 